Western University

Scholarship@Western

$4-2020$

\title{
A comparison of low temperature biology of Pieris rapae from Ontario, Canada, and Yakutia, Far Eastern Russia
}

Natalia G. Li

Ammosov North Eastern Federal University, li_natalia@mail.ru

Jantina Toxopeus

Western University, jantina.toxopeus@ucdenver.edu

Martin Moos

Czech Academy of Sciences, moos@bclab.eu

Jesper G. Sørensen

Aarhus University, jesper.soerensen@bios.au.dk

Brent J. Sinclair

Western University, bsincla7@uwo.ca

Follow this and additional works at: https://ir.lib.uwo.ca/biologypub

Part of the Biology Commons

\section{Citation of this paper:}

Li, Natalia G.; Toxopeus, Jantina; Moos, Martin; Sørensen, Jesper G.; and Sinclair, Brent J., "A comparison of low temperature biology of Pieris rapae from Ontario, Canada, and Yakutia, Far Eastern Russia" (2020). Biology Publications. 112.

https://ir.lib.uwo.ca/biologypub/112 
4 Natalia G. Li ${ }^{\mathrm{a}, 1}$, Jantina Toxopeus ${ }^{\mathrm{b}, 2, *}$, Martin Moos ${ }^{\mathrm{c}}$, Jesper G. Sørensen ${ }^{\mathrm{d}}$, Brent J. Sinclair ${ }^{\mathrm{b}}$

6 anstitute of Medicine, M.K. Ammosov North Eastern Federal University, Kulakovskogo Street

7 36, Yakutsk, Sahka Republic (Yakutia), Russia, 677007

8 bepartment of Biology, University of Western Ontario, 1151 Richmond St N, London, ON,

9 Canada, N6A 5B7

10 'Institute of Entomology, Biology Centre, Czech Academy of Sciences, Branišovská 1160/31,

11 České Budějovice, Czech Republic, 37005

12 department of Bioscience, Aarhus University, Ny Munkegade 116, Aarhus, Denmark, 8000

13 ' ${ }^{1}$ Current address: Cryoprotect LLC, Skolkovo Innovative Center, Nobel Street 7, Moscow,

14 Russia, 143026

$15{ }^{2}$ Current address: Department of Integrative Biology, University of Colorado, Denver, 1151

16 Arapahoe St, Denver, CO, United States of America, 80204

$17 \quad$ * Corresponding author

19 Emails: NGL, li_natalia@mail.ru; JT, jantina.toxopeus@ucdenver.edu; MM, moos@ bclab.eu;

20 JGS, jesper.soerensen@bios.au.dk; BJS, bsincla7@uwo.ca 


\section{Abstract}

23 Low temperatures limit the distribution and abundance of ectotherms. However, many insects

24 can survive low temperatures by employing one of two cold tolerance strategies: freeze

25 avoidance or freeze tolerance. Very few species can employ both strategies, but those that do

26 provide a rare opportunity to study the mechanisms that differentiate freeze tolerance and freeze

27 avoidance. We showed that overwintering pupae of the cabbage white butterfly Pieris rapae can

28 be freeze tolerant or freeze avoidant. A population of P. rapae in northeastern Russia (Yakutsk)

29 froze at c. $-9.3{ }^{\circ} \mathrm{C}$ and were freeze-tolerant in 2002-2003 when overwintered outside. However,

$30 \quad$ P. rapae from both Yakutsk and southern Canada (London) acclimated to milder laboratory

31 conditions in 2014 and 2017 froze at lower temperatures $\left(<-20^{\circ} \mathrm{C}\right)$ and were freeze-avoidant.

32 Summer-collected $P$. rapae larvae (collected in Yakutsk in 2016) were partially freeze-tolerant,

33 and decreased the temperature at which they froze in response to starvation at mild low

34 temperatures $\left(4^{\circ} \mathrm{C}\right)$ and repeated partial freezing events. By comparing similarly-acclimated $P$.

35 rapae pupae from both populations, we identified molecules that may facilitate low temperature

36 tolerance, including the hemolymph ice-binding molecules and several potential low molecular

37 weight cryoprotectants. Pieris rapae from Yakutsk exhibited high physiological plasticity,

38 accumulating cryoprotectants and almost doubling their hemolymph osmolality when

39 supercooled to $-15^{\circ} \mathrm{C}$ for two weeks, while London $P$. rapae population exhibited minimal

40 plasticity. We hypothesize that physiological plasticity is an important adaptation to extreme low

41 temperatures (i.e. in Yakutsk) and may facilitate the transition between freeze avoidance and

42 freeze tolerance.

\section{$44 \quad$ Key words}

45 cryoprotectants, freeze tolerance, freeze avoidance, metabolomics, plasticity 


\section{Graphical Abstract}

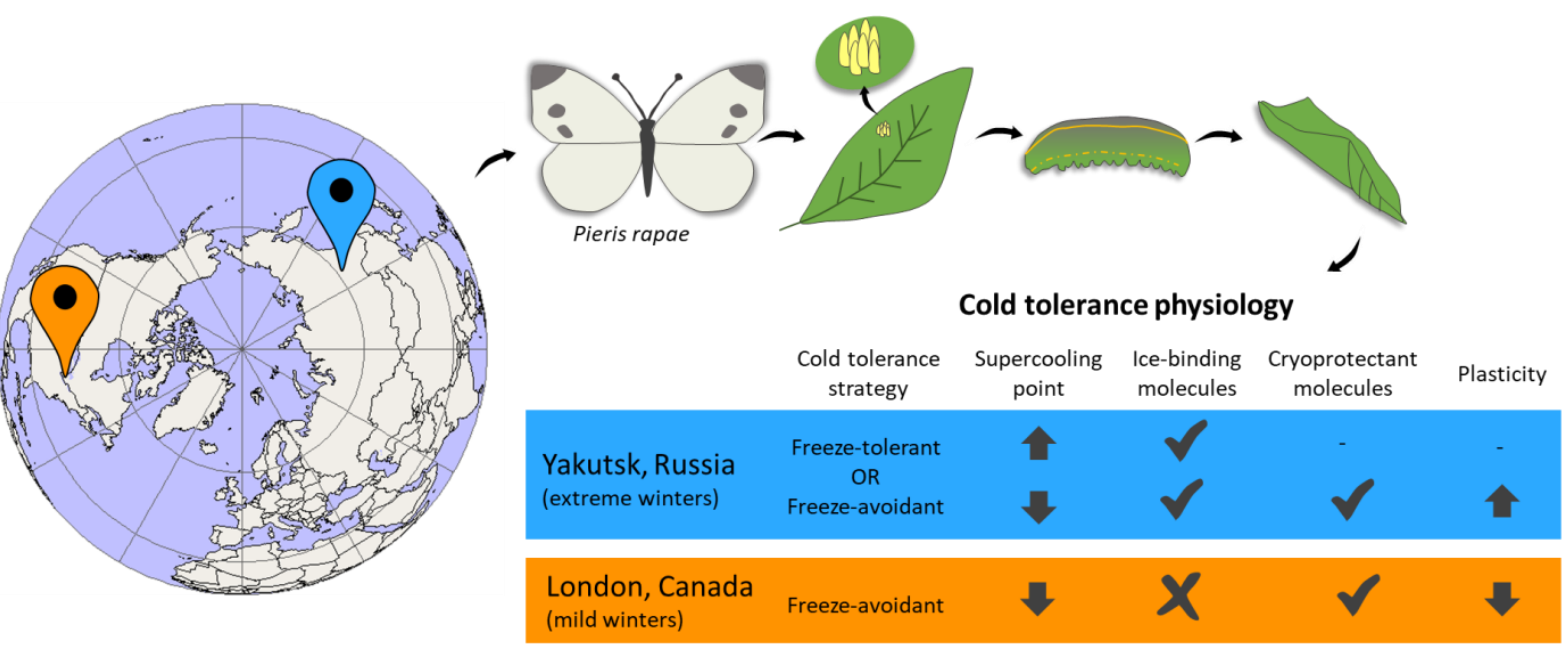

50 


\section{Introduction}

52 Low temperatures limit the distribution and abundance of many organisms, especially

53 ectotherms, whose body temperature usually reflects that of the environment (Clarke, 2017).

54 Most insects are chill-susceptible; they die of chilling injury at temperatures well above the 55 temperature at which ice formation begins (supercooling point, SCP; Salt, 1961; Sinclair et al.,

56 2015). Remarkably, many insects survive subzero temperatures by using one of two major cold

57 tolerance strategies: freeze-tolerant insects survive internal ice formation, while freeze-avoidant

58 insects depress the SCP and survive low temperatures as long as no internal ice forms (Lee,

59 2010; Sinclair et al., 2015). Both freeze avoidance and freeze tolerance are associated with the

60 accumulation of low molecular weight cryoprotectants (e.g. glycerol) and specialized molecules

61 and proteins that help to initiate and control the formation of ice crystals (freeze tolerance) or

62 prevent ice formation and growth (freeze avoidance) (Lee, 2010). Indeed, we have previously

63 hypothesized that freeze tolerance evolved from freeze avoidance based on this accumulation of

64 similar protective molecules (Toxopeus and Sinclair, 2018). However, it is difficult to compare

65 these two cold tolerance strategies without the confounding effects of phylogeny because we

66 lack sufficient phylogenetic resolution for appropriate among-species comparisons, and within-

67 species variation in cold tolerance strategy appears to be the exception rather than the rule.

69 Cold hardiness can vary substantially within a species, both among and within populations and

70 individuals (Sinclair et al., 2012). Differences in thermal tolerance among populations may result

71 from evolved differences (i.e. fixed genetic changes) or phenotypic plasticity (Mitchell et al.,

72 2011; Schou et al., 2017). Plasticity in cold tolerance can be induced by environmental cues

73 through acclimatization (in the field) or acclimation (in the laboratory) over long periods (days to

74 weeks), and over short periods (minute to hours) in the case of rapid cold hardening (RCH). For

75 example, the spring field cricket Gryllus veletis is chill-susceptible during the summer but

76 becomes freeze-tolerant in autumn (acclimatization) or when exposed to decreasing photoperiod

77 and fluctuating temperature in the laboratory (acclimation), a shift in cold tolerance associated

78 with a suite of molecular and physiological changes (Toxopeus et al., 2019a, b). In temperate and

79 polar climates, brief exposures to low temperatures, which can increase cold tolerance, are

80 common during autumn and winter (Marshall and Sinclair, 2012a). For example, the freeze- 
81 tolerant insects Eurosta solidaginis (Marshall and Sinclair, 2018) and Cyphoderris monstrosa

82 (Toxopeus et al., 2016) accumulate additional cryoprotectants after freezing. Cold tolerance can

83 also vary across development (Jensen et al., 2007); and many insects overwinter in diapause, a

84 state of developmental arrest associated with accumulation of energy reserves, metabolic rate

85 depression, and enhanced stress tolerance (Hahn and Denlinger, 2011).

87 While inter-individual and inter-population variation in cold tolerance is common, changes in cold tolerance strategy (e.g. switches between freeze tolerance and freeze avoidance) within a species are rare (Addo-Bediako et al., 2000). However, cold tolerance strategy can change over time: overwintering larvae of Dendroides canadensis and Cucujus clavipes were freeze-tolerant in the late 1970s, and became freeze-avoidant across their entire latitudinal range $\left(35^{\circ} \mathrm{N}\right.$ to $\left.46^{\circ} \mathrm{N}\right)$

92 in the early 1980s (Kukal and Duman, 1989). Cold tolerance strategy can also change with

93 environment: the linden bug Pyrrhocoris apterus and diapausing larvae of the drosophilid

94 Chymomyza costata can be freeze avoidant (supercooling to c. $-20{ }^{\circ} \mathrm{C}$ ), but are freeze-tolerant if

95 ice formation is nucleated by external ice at a high sub-zero temperature $\left(>-3{ }^{\circ} \mathrm{C}\right.$ ) (Rozsypal and

96 Koštál, 2018; Shimada and Riihimaa, 1988). These shifts in cold tolerance strategy can be

97 strongly influenced by environmental cues: C. costata acclimated to warm temperatures and long 98 days cannot survive freezing to $-32{ }^{\circ} \mathrm{C}$, while their counterparts acclimated to low temperatures 99 and short days can (Koštál et al. 2011). Finally, cold tolerance strategy can vary with geography: 100 overwintering Acanthocinus aedilis and Cossus cossus appear to survive freezing in the Far East 101 of Russia (Yakutsk) but are freeze-avoidant in northern Europe, where winters are milder (Li, 102 2016). Thus, natural variation in cold tolerance strategy is perhaps the best opportunity to 103 compare the mechanisms underlying freeze avoidance and freeze tolerance.

105 The cabbage white butterfly Pieris rapae is a potential model to study the mechanisms 106 underlying variation in cold tolerance and cold tolerance strategy (Li and Osakovskii, 2008).

107 This cosmopolitan agricultural pest is native to Europe and North Africa, and has colonized sub108 tropical to sub-polar environments across the northern hemisphere (Ryan et al., 2019). Pieris 109 rapae is bi- or tri-voltine across much of its distribution and overwinters as a pupa in facultative 110 diapause (Richards, 1940). Pieris rapae appears to use more than one cold tolerance strategy 
111 across its geographic range. Overwintering pupae from Estonia (Tallinn, average February

112 temperature $=-5.8^{\circ} \mathrm{C}$; en.climate-data.org) freeze at low temperatures (mean SCP $=-25.8^{\circ} \mathrm{C}$ )

113 and are freeze-avoidant (Sømme, 1982), while those in the Far East of Russia (Yakutia, average

114 February temperature $=-35.5^{\circ} \mathrm{C}$; en.climate-data.org) freeze at a temperature much higher than

115 the ambient temperature (mean $\mathrm{SCP}=-8.5^{\circ} \mathrm{C} ; \mathrm{Li}$ and Averenskii, 2007). $\mathrm{Li}$ and Averenskii

116 (2007) used respirometry to demonstrate that $P$. rapae pupae survived freezing, similar to other

117 Siberian insects.

119 Here, we compare cold tolerance strategy of $P$. rapae larvae and pupae from regions with

120 relatively extreme (Yakutsk, Russia) and mild (London, Canada) winters, using field and

121 laboratory measurements over a period of 15 years. To identify mechanisms that might support

122 switches in cold tolerance strategy, we compare cold tolerance and hemolymph composition (and

123 plasticity thereof) of Yakutsk and London pupae acclimated to common laboratory conditions.

124 While not all of our experiments were synchronized, our results suggest that P. rapae from

125 Yakutsk have highly plastic physiology, and that their cold tolerance strategy is not fixed.

\section{2. Material and methods}

1282.1 Insect collection, rearing, acclimatization, and acclimation

129 We collected P. rapae in the late summer (August or September) of 2002, 2014, 2016, and 2017

130 from Yakutsk, Russia $\left(62.0^{\circ} \mathrm{N}, 129.7^{\circ} \mathrm{E}\right)$ and/or London, Canada $\left(43.0^{\circ} \mathrm{N}, 81.3^{\circ} \mathrm{W}\right)$, and

131 acclimated or acclimatized them as summarized in Table 1 . The average minimum temperatures

132 (2019) in the coldest winter month (January) of these two collection locations are $-44.7^{\circ} \mathrm{C}$ and -

$13310.0^{\circ} \mathrm{C}$, respectively. Both populations are invasive (Ryan et al., 2019), but likely experience

134 limited gene flow due to their geographical separation. 
137 Table1. Collection and treatment of Pieris rapae populations used in this study. *

\begin{tabular}{lllll}
\hline $\begin{array}{l}\text { Collection } \\
\text { year }\end{array}$ & $\begin{array}{l}\text { Populations } \\
(N)\end{array}$ & Stage & Acclimation/acclimatization & Experiments \\
\hline 2002 & Yakutsk (18) & Pupa & $\begin{array}{l}\text { Acclimatization to local } \\
\text { overwintering conditions } \\
\text { (Oct 2002 to April 2003) }\end{array}$ & $\begin{array}{l}\text { Seasonal SCP and CTS } \\
\text { measurements }\end{array}$ \\
2014 & $\begin{array}{l}\text { Yakutsk (13), } \\
\text { London (2) }\end{array}$ & Pupa & $\begin{array}{l}\text { Acclimation to decreasing } \\
\text { fluctuating temperatures and } \\
\text { photoperiod (12 weeks) } \\
\text { Acclimation to room } \\
\text { temperature for up to 1 } \\
\text { week }\end{array}$ & $\begin{array}{l}\text { SCP and CTS measurements } \\
\text { following acclimation }\end{array}$ \\
& Yakutsk (16) & Larva and CTS measurements \\
& & & $\begin{array}{l}\text { SCllowing acclimation, } \\
\text { starvation, and repeated } \\
\text { freezing }\end{array}$ \\
2016 & Yakutsk (7), & Pupa & $\begin{array}{l}\text { Acclimation to 4 }{ }^{\circ} \mathrm{C}(12 \\
\text { weeks), } \pm \text { supercooling to } \\
-15^{\circ} \mathrm{C} \text { for weeks }\end{array}$ & $\begin{array}{l}\text { SCP and CTS measurements; } \\
\text { hemolymph composition } \\
\text { following acclimation and } \\
\text { supercooling }\end{array}$ \\
\hline
\end{tabular}

${ }^{*}$ CTS, cold tolerance strategy; $N$, samples size for experiments; SCP, supercooling point;

139 We collected Yakutsk P. rapae as late (third) instar larvae (caterpillars) from cabbage fields in 140 all four years of the study. We maintained larvae at room temperature $\left(\right.$ c. $\left.22{ }^{\circ} \mathrm{C}\right)$ under natural 141 light conditions with daily access to fresh organic cabbage until pupation $(2002,2014,2017)$ or 142 until use in cold tolerance experiments (2016). In 2002, we transferred individuals to $4{ }^{\circ} \mathrm{C}$ (total 143 darkness) within two days of pupation (late August) and then transferred them to an outdoor, 144 snow-covered field cage (also in total darkness) from October 2002 until April 2003 in Yakutsk.

145 Groups of two or three pupae were transferred back to the laboratory each month for cold 146 tolerance experiments. In 2014 and 2017, we transported pupae in individual containers (1.7 ml 147 microcentrifuge tubes with a punctured lid) to the University of Western Ontario (London, 148 Canada) on ice for two days (2014) or at room temperature for two weeks (2017). We acclimated 149 these $P$. rapae to the same laboratory conditions as the pupae collected in London (described 150 below) prior to use in cold tolerance experiments.

152 We collected London P. rapae as adults from an urban garden in August and September in 2014 153 and 2017. We maintained adults in a $61 \times 61 \times 61 \mathrm{~cm}$ tent-shaped bug dorm (BioQuip, Compton, $154 \mathrm{CA}, \mathrm{USA})$ at room temperature $\left(\right.$ c. $\left.22^{\circ} \mathrm{C}\right)$ under natural light conditions with fresh organic 
155 cabbage for oviposition and artificial nectar (10\% honey solution) replenished three times per 156 week. We reared offspring of these adults under the same conditions. In 2014, individuals that 157 pupated by mid-September were transferred (along with Yakutsk pupae) to an acclimation with 158 decreasing, fluctuating temperatures and photoperiod for 12 weeks (until early December) in a 159 Sanyo MIR 154 incubator (Sanyo Scientific, Bensenville, IL, USA) prior to use in cold tolerance 160 experiments. Temperatures and photoperiod conditions were selected to approximately mimic 161 autumn conditions in London, Canada (Table 2). In 2017, pupae were kept at room temperature 162 for 2 weeks and then transferred along with Yakutsk pupae to $4{ }^{\circ} \mathrm{C}$ (total darkness) for 12 weeks 163 prior to use in experiments. Pupae that were not in diapause (i.e. eclosed during those two weeks 164 at temperature) or that were parasitized were excluded from cold tolerance and plasticity 165 experiments (described below).

166 Table 2. Temperature and photoperiod acclimation conditions over 12 weeks used for $P$. rapae 167 pupae collected in 2014. Each condition was used for 2 weeks (14 days). Pupae were exposed to 168 the high and low temperatures for $12 \mathrm{~h}$ each.

169

\begin{tabular}{cccc}
\hline Weeks & \multicolumn{2}{c}{ Temperature $\left({ }^{\circ} \mathrm{C}\right)$} & $\begin{array}{c}\text { Photoperiod } \\
(\mathrm{L}: \mathrm{D}, \mathrm{h})\end{array}$ \\
\cline { 2 - 3 } & High & Low & \\
\hline 1 and 2 & 17 & 15 & $11: 13$ \\
3 and 4 & 15 & 10 & $11: 13$ \\
5 and 6 & 15 & 8 & $9: 15$ \\
7 and 8 & 12 & 6 & $9: 15$ \\
9 and 10 & 8 & 4 & $8: 16$ \\
11 and 12 & 4 & 2 & $8: 16$ \\
\hline
\end{tabular}

172 To determine the SCP of individuals from all four collection years, we cooled $P$. rapae pupae 173 and larvae at a rate of $1{ }^{\circ} \mathrm{C} \mathrm{min}^{-1}$ from room temperature to the SCP. Each individual was cooled 174 in its own container (e.g. $1.7 \mathrm{ml}$ microcentrifuge tube), in contact with a Type T copper175 constantan thermocouple (Omega Engineering, Laval, QC, Canada) to continuously measure 176 temperature, either through connection to a INSEIS L 120 E Line Recorder (2002-2003, 2016;

177 Wavefield Inseis, Bergen, Germany) or PicoLog TC-08 unit interfaced to a computer with 178 PicoLog v5.24.1 software (2014, 2017; Pico Technology, Cambridge, UK). Each container was 179 cooled in either a TC-G-180 Binder climatic chamber (2002-2003, 2016; Tuttlingen, Germany) 
180 or an aluminum block connected to a Lauda Proline 3530 recirculating bath containing methanol 181 (2014, 2017; Lauda, Würzburg, Germany). The SCP was defined at the lowest temperature 182 observed prior to exotherm formation (increase in temperature associated with the exothermic 183 process of ice formation; Sinclair et al., 2015). We compared SCP among groups using ANOVA 184 with a Tukey's post-hoc test. All statistical analyses were conducted in R version 3.2.2 (R-Core185 Team, 2019).

187 We determined the cold tolerance strategy of $P$. rapae in all four collection years. Following the 188 acclimation or acclimatization described in Table 1, we cooled pupae as described above to 189 either the SCP or a temperature just above the SCP, immediately transferred them to room 190 temperature and assessed survival (Sinclair et al., 2015). The methods to determine survival 191 included: respirometry of pupae one day post-thaw (2002-2003; details below), eclosion of 192 pupae as adults (2014), and both respirometry of pupae five days post-cold and eclosion as adults 193 (2017). We classified populations as freeze-tolerant if individuals survived following a 194 completed exotherm and freeze avoidant if only unfrozen individuals survived (Sinclair et al., 195 2015). In 2017, for a subset of pupae, we inoculated freezing at a high sub-zero temperature (c. $1964{ }^{\circ} \mathrm{C}$ ) using external application of a silver iodide slurry (cf. Toxopeus et al., 2019b).

198 To determine larval cold tolerance strategy, we cooled field-collected third instar larvae (2016)

199 to their SCP and compared survival of larvae returned to room temperature soon after either full 200 or partial exotherm formation. We defined survival as the ability of larvae to move without 201 stimulus or prompting after three days at room temperature. We classified populations as 202 partially freeze-tolerant if individuals survived following partial, but not full, exotherm 203 formation (Sinclair, 1999). To investigate plasticity in larval cold tolerance, we measured the 204 SCP of larvae that were actively feeding at room temperature, and larvae that were starved for 205 one or five days at $4{ }^{\circ} \mathrm{C}$. Because we determined that larvae could survive partial freezing, we 206 tested whether repeated short freeze treatments (such as might occur during autumn cold snaps) 207 impacted larval SCP and survival. These larvae were cooled to their SCP, immediately returned 208 to room temperature prior to exotherm completion, and held at room temperature for c. 30 
minutes between freeze treatments. We used a linear regression to determine if SCP changed as

210 the number of freeze treatments increased.

\subsection{Respirometry}

213 We measured $\mathrm{CO}_{2}$ emission by cold-exposed pupae to determine survival in 2002-2003 and

214 2017. All measurements for survival were conducted at $20^{\circ} \mathrm{C}$ for expediency; diapause pupae 215 exhibit a long (> $6 \mathrm{~h}$ ) discontinuous gas exchange cycle at lower temperatures (e.g. $\left.10^{\circ} \mathrm{C}\right)$. In

216 2002-2003, we conducted respirometry using an Engelmann constant pressure respirometer as 217 described previously (Zachariassen et al., 1987). In 2017, we used Sable Systems flow-through 218 respirometry (Sable Systems International, Las Vegas) as described previously (Toxopeus et al., 219 2019b). For flow-through respirometry, we corrected $\mathrm{CO}_{2}$ production to 5 min baseline 220 measurements and calculated the rate of $\mathrm{CO}_{2}$ production $\left(\dot{V} \mathrm{CO}_{2}\right.$; Lighton, 2018). Pupae with a 221 mass-specific $\dot{V} \mathrm{CO}_{2}$ greater than $40 \mu \mathrm{CO}_{2} \mathrm{~g}^{-1} \mathrm{~h}^{-1}$ were classified as alive. In 2017, five of the 222 six pupae (London and Yakutsk populations) that we classified as 'alive' based on respirometry 223 also eclosed as adults, indicating that respirometry is a reliable metric of survival in diapausing $224 P$. rapae. We also conducted respirometry on a small number of diapause and non-diapause 225 pupae from the 2017 London population to characterize typical gas exchange patterns at $10{ }^{\circ} \mathrm{C}$ 226 and $20{ }^{\circ} \mathrm{C}$. We classified pupae as non-diapause if they eclosed within two weeks of pupation at 227 room temperature, while diapause pupae had no apparent development during this time. We 228 compared $\mathrm{CO}_{2}$ production of diapause and non-diapause pupae at both temperatures using 229 ANCOVA with mass as a covariate.

\subsection{Plasticity of hemolymph composition}

232 We measured hemolymph osmolality, thermal hysteresis, and metabolite composition of Yakutsk 233 and London pupae collected in 2017. To determine baseline hemolymph composition, we 234 extracted hemolymph from pupae that were acclimated as described above (2-3 weeks at room 235 temperature followed by 12 weeks at $4{ }^{\circ} \mathrm{C}$ ). To determine whether hemolymph composition was 236 plastic, we extracted hemolymph from pupae that were acclimated in the same way, then 237 supercooled at $-15{ }^{\circ} \mathrm{C}$ for two weeks, and returned to $4{ }^{\circ} \mathrm{C}$ for five days. We kept these pupae at 
$4{ }^{\circ} \mathrm{C}$ for five days to allow them time to recover and potentially synthesize cryoprotectants post239 supercooling. All pupae survived this supercooling treatment, as determined by respirometry at $20{ }^{\circ} \mathrm{C}$. Following respirometry, we extracted up to $40 \mu \mathrm{l}$ of hemolymph from each individual by making a small posterior incision and pipetting out the liquid using a $10 \mu \mathrm{l}$ micropipette.

242 Hemolymph samples were flash-frozen in liquid nitrogen and stored at $-80{ }^{\circ} \mathrm{C}$ until analysis.

244 We measured hemolymph osmolality using a nanolitre osmometer (Otago Osmometers, 245 Dunedin, New Zealand), as described previously (Toxopeus et al., 2019b). Briefly, we used the 246 osmometer to rapidly freeze small volumes of hemolymph, determined osmolality from the 247 melting point of the solution, and calculated thermal hysteresis from the difference between 248 melting and freezing points (Crosthwaite et al., 2011). We also noted ice crystal shape 249 (hexagonal or spicular) during this process to identify the presence of potential ice-binding 250 molecules. We compared the osmolality of Yakutsk and London pupae before and after supercooling using a two-way ANOVA.

To compare the hemolymph composition among pupae, we quantified low molecular weight metabolites via targeted metabolomics in $10 \mu 1$ samples of hemolymph, as previously described (Rozsypal et al., 2018; Toxopeus et al., 2019a). Briefly, we lyophilized hemolymph samples, and sent them to the Laboratory of Analytical Biochemistry at the Czech Academy of Sciences for metabolomic analysis. The samples were rehydrated and homogenized in $400 \mu$ of methanol: acetonitrile: water mixture (2:2:1, v/v/v) containing internal standards (p-fluoro-DLphenylalanine, methyla-D-glucopyranoside; both at a final concentration of $200 \mathrm{nmol} / \mathrm{ml}$; Sigma-Aldrich). The TissueLyser LT (Qiagen, Hilden, Germany) was set to $50 \mathrm{~Hz}$ for $5 \mathrm{~min}$

261 (with a rotor pre-chilled to $-20^{\circ} \mathrm{C}$ ). Homogenization was repeated twice and the two supernatants

262 from centrifugation at $20000 \times \mathrm{g}$ for $5 \mathrm{~min}$ at $4{ }^{\circ} \mathrm{C}$ were combined. To quantify acidic

263 metabolites (e.g. amino acids), samples were derivatized by ethylchloroformate in

264 pyridine/ethanol, and extracted in chloroform (for GC-MS) or $30 \%$ methanol (for LC-MS). To

265 quantify sugars and polyols, samples were derivatized by oximation and methylsilylation, and

266 dissolved in iso-octane for analysis by GC-FID. Each metabolite was quantified ( $\mathrm{nmol} / \mu \mathrm{l}$

267 hemolymph) by comparison to a standard curve generated for that metabolite. We conducted 
268 principal component analysis (PCA) using the calibrate package in R to compare metabolite 269 profiles of individuals from different treatments and populations. To do so, we first standardized 270 metabolite concentrations by subtracting each concentration from the mean and dividing by the 271 standard deviation of that metabolite. We identified metabolites of interest as those that loaded 272 strongly onto principal components (PCs) 1 and 2. We also determined whether individual 273 metabolites of interest differed in concentration with treatment or population using two-way 274 ANOVAs.

\section{Results}

\subsection{Cold tolerance strategies of $\mathrm{P}$. rapae across time, population, and treatment}

278 In 2002-2003, diapausing pupae of $P$. rapae overwintering outside in Yakutsk froze at moderately high sub-zero temperatures $\left(-7.3\right.$ to $\left.-12.2^{\circ} \mathrm{C}\right)$ and (because all individuals that froze recovered) we classified this population as freeze tolerant (Table 3). Pupal SCP in this winter-

281 acclimatized group was seasonally plastic (Fig. 1A): the highest SCP values were recorded in the 282 autumn (November) and spring (April), and the lowest SCP values in mid-winter (January). 283 Conversely, P. rapae pupae from Yakutsk that were collected in the late summer of 2014 or 2842017 and acclimated to laboratory conditions in London, Canada froze at between -20.6 and $28526.5^{\circ} \mathrm{C}$, and did not survive freezing, but did survive cooling to temperatures above the SCP 286 (Table 3). We classified these populations as freeze avoidant. Pupae from London that were 287 collected and acclimated in 2014 or 2017 were similarly freeze-avoidant and froze between -20.9 288 and $-24.7^{\circ} \mathrm{C}$ (Table 3). No pupae collected in 2017 survived freezing when ice formation was 289 nucleated with silver iodide.

291 We classified $P$. rapae larvae collected from Yakutsk in late summer (August) of 2016 as 292 partially freeze tolerant: they froze at moderate sub-zero temperatures $\left(-8.8\right.$ to $\left.-13{ }^{\circ} \mathrm{C}\right)$ and they 293 survived ice formation associated with partial exotherm completion, but did not survive if 294 exotherm formation completed (Table 3). Larval SCP was plastic: if larvae were partially frozen 295 several times in a row, SCP tended to decrease with each subsequent freeze treatments, reaching 
296 values as low as $-19{ }^{\circ} \mathrm{C}$ (Fig. 1B). When starved and kept at $4{ }^{\circ} \mathrm{C}$ for five days, larval SCP

297 decreased by c. $1^{\circ} \mathrm{C}$, in concert with mass loss (c. $25 \%$ ) and clearing of gut contents (Table S1).

Table 3. Mean supercooling points (SCPs) and cold tolerance strategy of Pieris rapae third 300 instar larvae and diapausing pupae. Treatments of individuals prior to freezing or supercooling 301 are summarized in Table 1. The fraction of individuals that survived freezing, partial freezing, or 302 supercooling are indicated for each group.

\begin{tabular}{llllllll}
\hline $\begin{array}{l}\text { Collection } \\
\text { year }\end{array}$ & Population & Stage & $\begin{array}{l}\text { Mean SCP } \\
\pm \text { s.e.m. } \\
\left({ }^{\circ} \mathrm{C}\right)^{*}\end{array}$ & $\begin{array}{l}N \text { survived/ } \\
N \text { frozen }\end{array}$ & $\begin{array}{l}N \text { survived/ } \\
N \text { partially } \\
\text { frozen }\end{array}$ & $\begin{array}{l}N \text { survived/ } \\
N \text { super- } \\
\text { cooled }\end{array}$ & $\begin{array}{l}\text { Cold tolerance } \\
\text { strategy }\end{array}$ \\
\hline 2002 & Yakutsk & Pupa & $-9.3 \pm 0.3^{\mathrm{a}}$ & $18 / 18$ & n.d. & n.d. & Freeze tolerant \\
\hline 2014 & London & Pupa & $-22.6 \pm 1.7^{\mathrm{b}}$ & $0 / 2$ & n.d. & n.d. & Cannot discern \\
& Yakutsk & Pupa & $-23.6 \pm 0.7^{\mathrm{b}}$ & $0 / 9$ & n.d. & $2 / 4$ & Freeze avoidant \\
\hline 2016 & Yakutsk & Larva & $-10.2 \pm 0.5^{\mathrm{a}}$ & $0 / 8$ & $8 / 8$ & n.d. & $\begin{array}{l}\text { Partially freeze } \\
\text { tolerant }\end{array}$ \\
\hline 2017 & London & Pupa & $-24.4 \pm 0.3^{\mathrm{b}}$ & $0 / 3$ & n.d. & $3 / 3$ & Freeze avoidant \\
& Yakutsk & Pupa & $-20.8 \pm 0.8^{\mathrm{b}}$ & $0 / 2$ & n.d. & $3 / 5$ & Freeze avoidant \\
\hline
\end{tabular}

304 *Differences in mean SCP among groups are indicated by different letters (ANOVA, Tukey's 305 post-hoc test, $P<0.05$ ). 

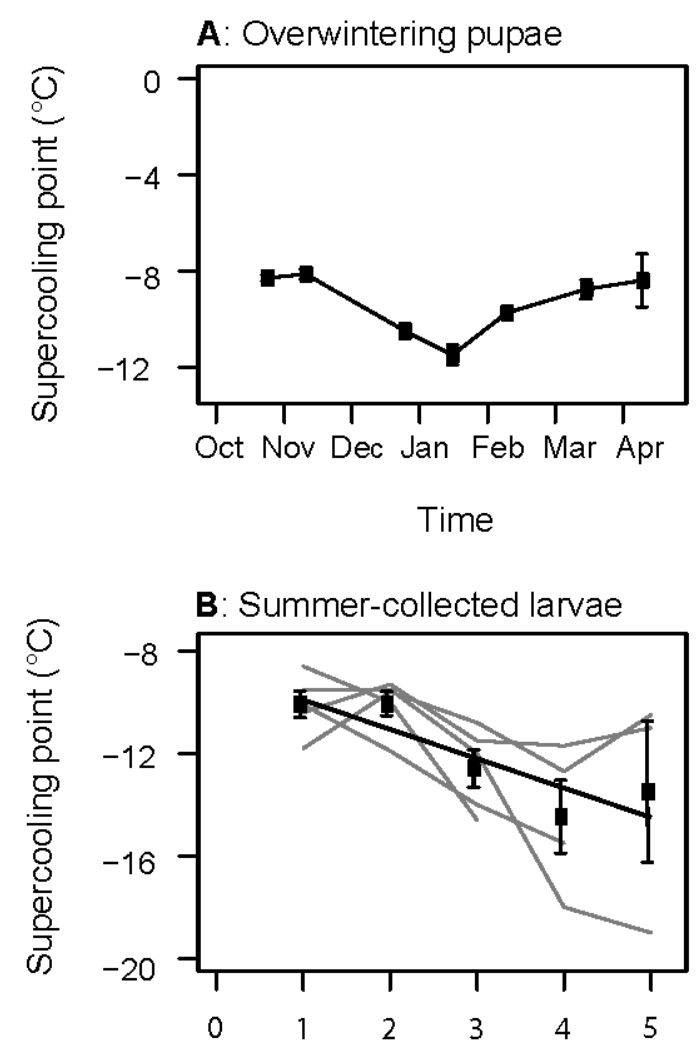

Number of freeze-thaw cycles

309 Figure 1. Mean SCP of Pieris rapae (A) pupae overwintering in Yakutsk from October 2002 to 310 April 2003 and (B) larvae collected in 2016 and partially frozen up to five consecutive times.

311 Overwintering pupae were kept in darkness in a snow-covered overwintering field cage, and two 312 or three individuals were removed each month for SCP measurements. Larvae were cooled to 313 their SCP, returned to room temperature prior to exotherm completion, and held at room 314 temperature for $30 \mathrm{~min}$ between freeze treatments. Mean \pm s.e.m. is displayed for each time point 315 or freeze treatment; solid black line indicates the linear regression. Data from each larva are 316 represented by grey lines, and mean SCP decreased as the number of freeze-thaw cycles 317 increased $\left(F_{20,1}=10.77, P=0.004\right)$. Small error bars are obscured by symbols. 
319 Diapausing pupae from the London population (2017) exhibited discontinuous gas exchange at 320 both $10{ }^{\circ} \mathrm{C}$ and $20^{\circ} \mathrm{C}$, while non-diapause pupae exhibited continuous gas exchange at $20^{\circ} \mathrm{C}$ and 321 discontinuous gas exchange at $10{ }^{\circ} \mathrm{C}$ (example respirometry traces in Fig. 2A-D). Non-diapause 322 pupae had higher metabolic rates than diapause pupae at both temperatures (Fig. 2E). We show 323 an example respirometry trace from a dead pupa in Fig. 2F.

\subsection{Plasticity of hemolymph composition}

326 Pieris rapae pupae had hemolymph osmolality ranging from 355 to 505 mOsm when acclimated 327 to room temperature for two weeks followed by $4{ }^{\circ} \mathrm{C}$ for 12 weeks (2017). The hemolymph 328 osmolality of London pupae was c. 115 mOsm higher than that of Yakutsk pupae following this 329 acclimation (Fig. 3). When acclimated pupae were subsequently supercooled to $-15{ }^{\circ} \mathrm{C}$ for two 330 weeks and returned to $4{ }^{\circ} \mathrm{C}$ for five days, hemolymph osmolality of Yakutsk pupae almost 331 doubled, while that of London pupae did not change compared to pupae that were only held at 4 $332{ }^{\circ} \mathrm{C}$ (Fig. 3). We detected negligible thermal hysteresis $\left(<0.05{ }^{\circ} \mathrm{C}\right)$ in all hemolymph samples.

333 However, most frozen hemolymph samples from Yakutsk pupae contained hexagonal or spicular 334 ice crystals, suggesting $P$. rapae have hemolymph ice-binding proteins (Table S2). Ice crystals in 335 hemolymph from London were circular, suggesting a lack of ice-binding molecules. 

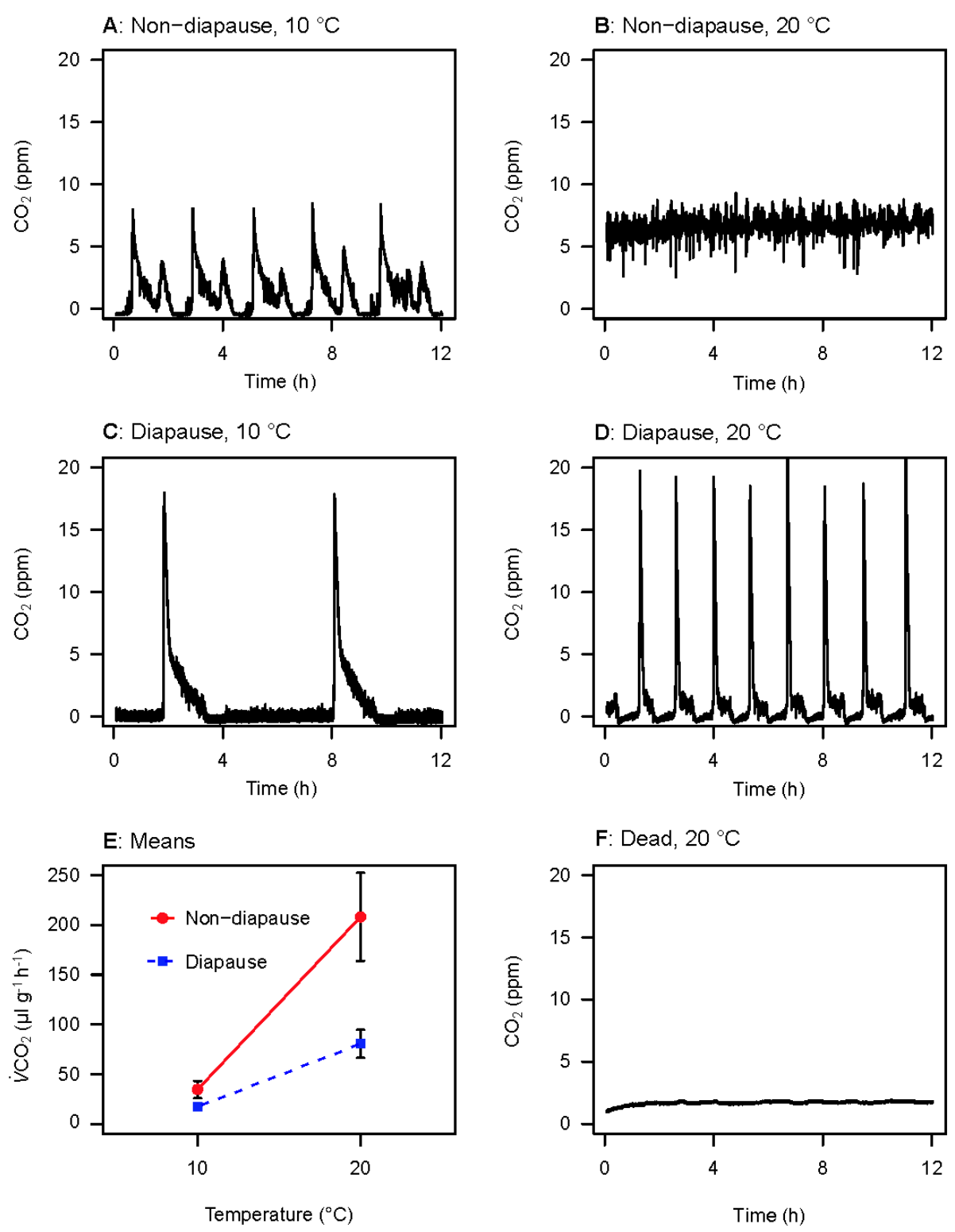

Figure 2. Example respirometry traces of $(\mathbf{A}, \mathbf{B})$ non-diapause, $(\mathbf{C}, \mathbf{D})$ diapause Pieris rapae pupae from London in 2017. (E) Mean ( \pm s.e.m.) rates of $\mathrm{CO}_{2}$ production $\left(\dot{V} \mathrm{CO}_{2}\right)$ for three diapause and non-diapause pupae from the same population. Diapause and temperature impacted mean rates of $\mathrm{CO}_{2}$ production (ANCOVA, Diapause status: $F_{12,1}=9.77, P=0.017$;

Temperature: $F_{12,1}=26.52, P=0.001$; Diapause status $\times$ Temperature: $F_{12,1}=5.71, P=0.048$ ). (F) Example respirometry trace of a dead $P$. rapae pupa. $\mathrm{CO}_{2}$ production was measured over a

$34412 \mathrm{~h}$ period at $10^{\circ} \mathrm{C}$ or $20^{\circ} \mathrm{C}$. 


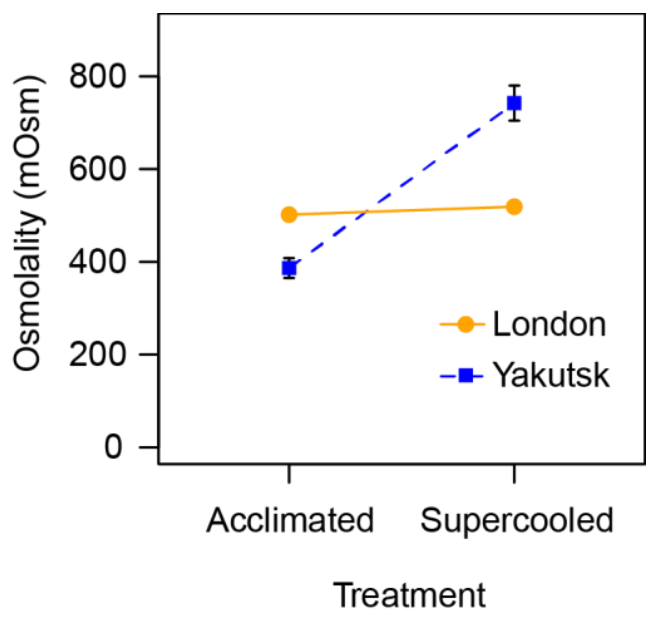

347 Figure 3. Hemolymph osmolality (mOsm) of Pieris rapae diapause pupae. London and Yakutsk 348 pupae in 2017 were acclimated at $4{ }^{\circ} \mathrm{C}$ for 12 weeks ('acclimated'), and a subset were then 349 cooled to $-15{ }^{\circ} \mathrm{C}$ for two weeks ('supercooled') and returned to $4{ }^{\circ} \mathrm{C}$ for five days prior to 350 osmolality measurement. Mean \pm s.e.m. of three pupae is displayed for each population $\times$ 351 treatment combination. Small error bars are obscured by symbols. Supercooling increased 352 osmolality of Yakutsk pupae (ANOVA, Population: $F_{11,1}=3.32, P=0.11$; Treatment: $F_{11,1}=$ 353 72.41, $P<0.001$; Population $\times$ Treatment: $\left.F_{11,1}=75.33, P<0.001\right)$.

355 We quantified 46 hemolymph low molecular weight metabolites from these same pupae and 356 analyzed the impact of supercooling on metabolite composition. The metabolite profile of 357 Yakutsk pupae changed substantially with supercooling, whereas we saw little shift in the 358 hemolymph composition of London pupae (Fig. 4A). Most of the variation in Yakutsk 359 hemolymph composition was associated with metabolites along PC 1, including amino acids

360 (alanine, isoleucine, leucine, phenylalanine, proline, serine, threonine), polyols (sorbitol), and 361 citric acid cycle intermediates (aconitic acid, ketoglutaric acid, citric acid) (Fig. 4B).

362 Approximately 220 mOsm of the c. 350 mOsm increase in Yakutsk pupa osmolality could be 363 accounted for by the accumulation of low molecular weight metabolites, many of which are 364 potential cryoprotective molecules. The metabolites with moderate increases $(>20 \mathrm{mM})$ in 365 concentration following supercooling in the Yakutsk population were proline, alanine, 366 glutamine, sorbitol, and fructose (Fig. 5). Small increases (> $5 \mathrm{mM}$ ) were observed in leucine, 367 isoleucine, threonine, glycerol, mannitol, and trehalose (Fig. 5). 


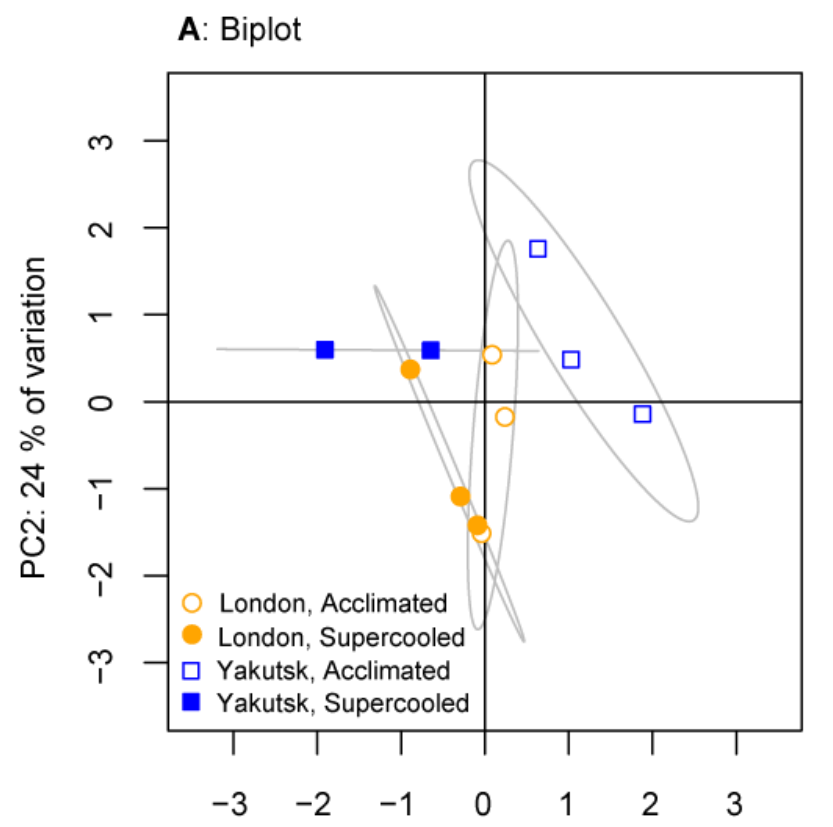

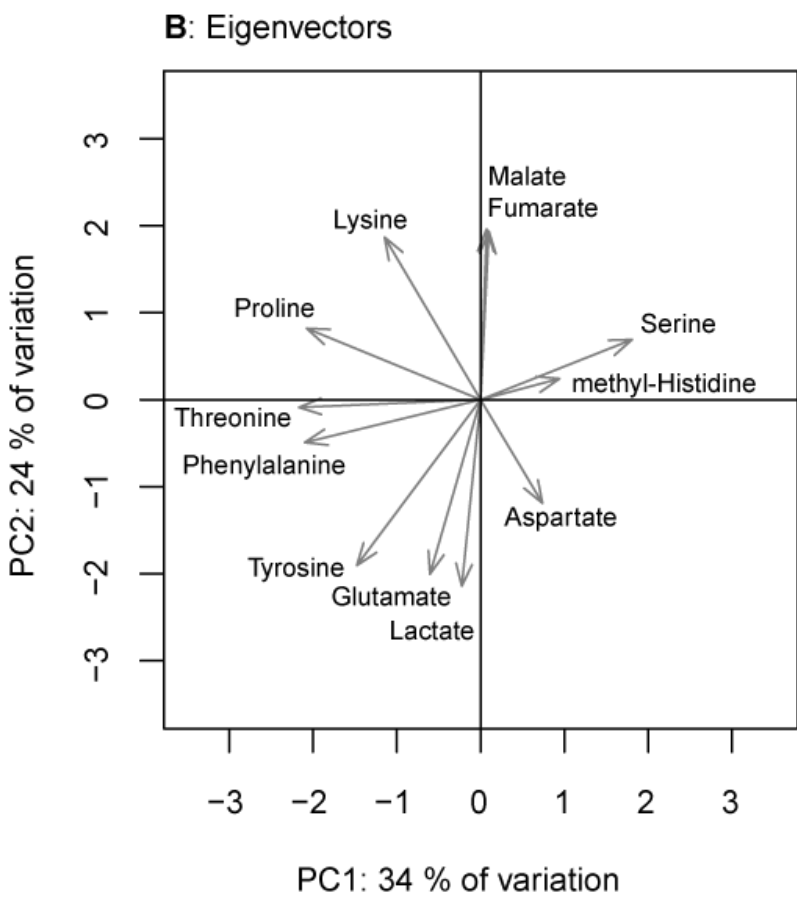

Figure 4. Principal component analysis (PCA) of hemolymph metabolites in London and Yakutsk pupae collected and acclimated in 2017. Pupae were acclimated at $4{ }^{\circ} \mathrm{C}$ for 12 weeks ('acclimated'), and a subset were then cooled to $-15^{\circ} \mathrm{C}$ for two weeks ('supercooled') and returned to $4{ }^{\circ} \mathrm{C}$ for five days prior to quantification of metabolites. (A) Biplot of the PCA, with each pupal hemolymph sample represented by a point; the $95 \%$ confidence interval is represented by an ellipse. (B) Eigenvectors of the 12 metabolites that loaded most strongly onto PCs 1 and 2; longer arrows indicate a greater impact on the PC. 


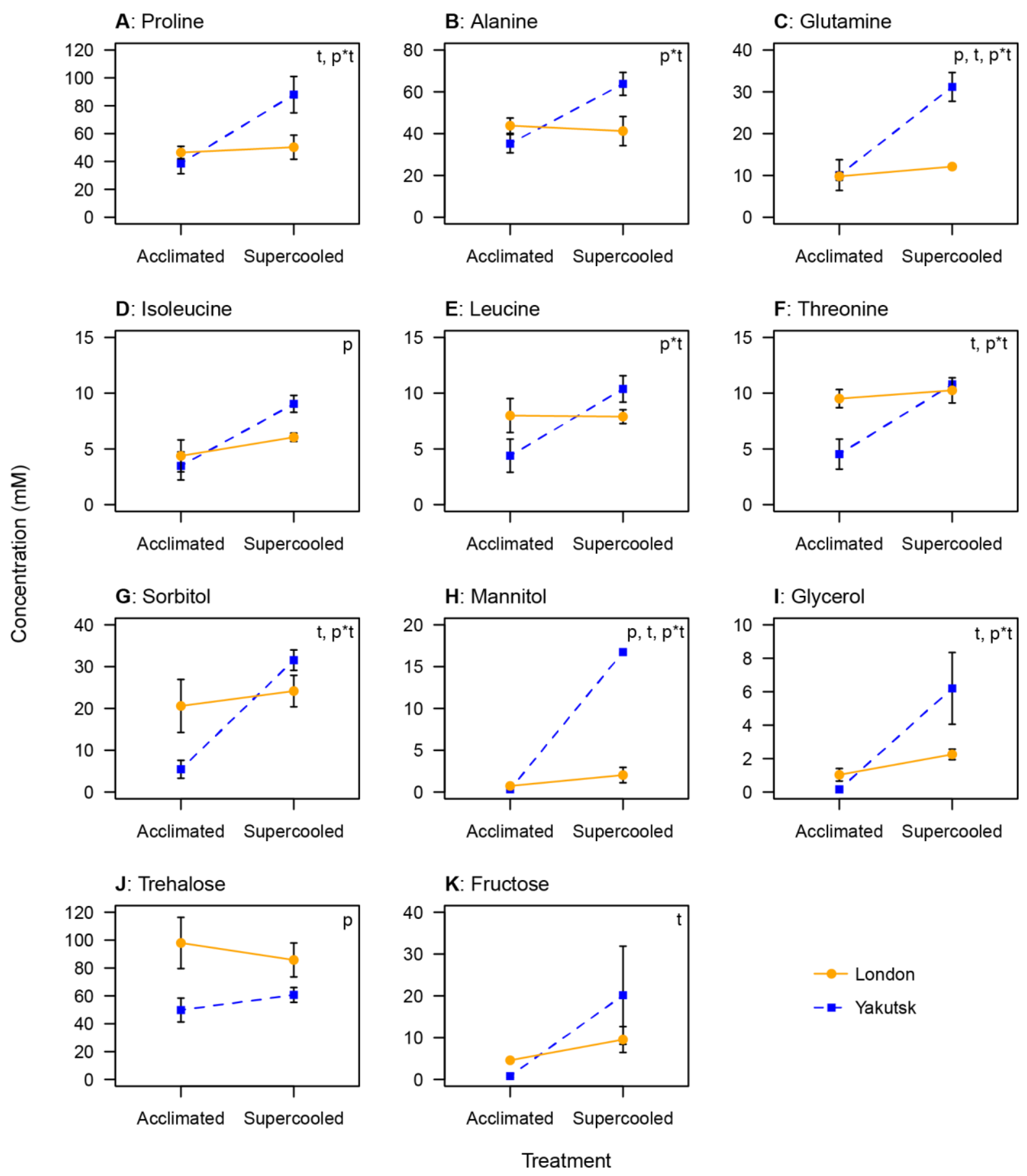

Figure 5. Hemolymph concentrations (mM) of (A-F) amino acids, (G-I) polyols, and (J-K) sugars with moderate to substantial changes in concentration following supercooling. London (orange) and Yakutsk (blue) pupae in 2017 were kept at $4{ }^{\circ} \mathrm{C}$ for 12 weeks ('acclimated'), and a subset were then cooled to $-15^{\circ} \mathrm{C}$ for two weeks ('supercooled') and returned to $4{ }^{\circ} \mathrm{C}$ for five days prior to quantification of metabolites. Mean \pm s.e.m. of three pupae is displayed for each Population $\times$ Treatment combination. Small error bars are obscured by symbols. Significant effects of Population $(\mathrm{p})$, Treatment $(\mathrm{t})$, or Population $\times$ Treatment $(\mathrm{p} * \mathrm{t})$ interaction on cryoprotectant concentration are indicated in each panel (ANOVA, $P<0.05$ ). 


\section{Discussion}

4.1 The cold tolerance strategy of Pieris rapae varies with population, time, and acclimation

389 Overwintering $P$. rapae pupae can be either freeze tolerant or freeze avoidant. Pupae

390 overwintering outdoors in Yakutsk, Russia in 2002-2003 were freeze tolerant (see also Li and

391 Averenskii, 2007), whereas diapausing P. rapae from the milder climate of London, Canada

392 were freeze avoidant (cf. Estonian populations; Sømme, 1982). Although field-collected Yakutsk

393 pupae in 2002-2003 were freeze tolerant, Yakutsk pupae acclimated to laboratory conditions in

3942014 and 2017 were freeze avoidant. It should be noted that we had low sample sizes for

395 determining cold tolerance strategy; however, cold tolerance strategy is binary in cold-tolerant

396 species (Sinclair et al. 2015). There was limited variability in survival results (e.g. all 2002-2003

397 Yakutsk pupae survived freezing, whereas no pupae survived freezing in 2014 or 2017), and we

398 are therefore confident in these results. We propose two hypotheses for the shift we observed in

399 cold tolerance strategy: 1) the P. rapae population in Yakutsk has lost its ability to become

400 freeze-tolerant over time; or 2) the laboratory acclimation conditions we used in 2014 and 2017

401 were insufficient to induce freeze tolerance.

402

403 There is precedent for hypothesis 1 (loss of freeze tolerance over time) in the beetles $D$.

404 canadensis and C. clavipes (Kukal and Duman, 1989). Both of these species were freeze-tolerant

405 when first studied, but individuals collected from the same location in subsequent years were

406 freeze avoidant, apparently due to the loss of ice nucleating agents (Kukal and Duman, 1989).

407 We saw a loss of freeze tolerance in P. rapae pupae collected from Yakutsk between 2002 and

4082014 , concurrent with winter warming: air temperatures were below $-50{ }^{\circ} \mathrm{C}$ in $2002-2003$, but

409 rarely dropped below $-40{ }^{\circ} \mathrm{C}$ in 2014-2015 (en.climate.org). However, we cannot truly assess

410 hypothesis 1 in this population because the freeze-tolerant pupae we collected in 2002-2003 were

411 treated very differently (overwintered outdoors) from the freeze-avoidant pupae we studied in

4122014 and 2017 (laboratory-acclimated to mild conditions).

414 We favour hypothesis 2 (that we could not artificially induce freeze tolerance in Yakutsk pupae)

415 because we expect that freeze avoidant pupae would not be able to suppress their SCP 
416 sufficiently to remain unfrozen during a Yakutian winter. Pieris rapae pupae overwinter attached

417 to the leaves and stems of Brassica plants (e.g. cabbage), and may be directly exposed to the

418 winter air temperatures unless winter precipitation is substantial. Even though snow cover could

419 provide some insulation, winter air temperatures below $-40{ }^{\circ} \mathrm{C}$ (en.climate-data.org) would likely

420 making it very difficult for $P$. rapae to avoid internal ice formation (Ring, 1982). We therefore

421 expect freeze tolerance to be a necessary cold adaptation mechanism for Yakutsk P. rapae,

422 similar to other overwintering insects in regions with extreme low temperatures (Li, 2016;

423 Toxopeus and Sinclair, 2018). Conversely, freeze avoidance is likely sufficient for $P$. rapae to

424 overwinter in milder climates. In London, minimum winter air temperatures are rarely below -24

$425{ }^{\circ} \mathrm{C}$, and there is significant buffering by snow cover (Marshall and Sinclair, 2012b), which means 426 that $P$. rapae likely remain unfrozen (and alive) during winter.

428 We suggest that the laboratory acclimation conditions in 2014 and 2017 lacked critical 429 environmental cues that induce physiological changes required for freeze tolerance in Yakutsk $P$. 430 rapae. For comparison, G. veletis requires a complex acclimation regime to induce freeze 431 tolerance, including decreasing day length combined with decreasing fluctuating temperatures 432 over six weeks (Toxopeus et al., 2019b). If either day length or temperature cues are missing, $G$. 433 veletis does not become freeze tolerant (Toxopeus et al., 2019b). The autumn temperatures in 434 Yakutsk are considerably lower and the days are much shorter than those in London, so our 435 laboratory acclimations (e.g. Table 2) likely lacked the multiple cues required to induce freeze 436 tolerance. Thus, although the $P$. rapae we collected in 2014 and 2017 were freeze-avoidant, we 437 expect that $P$. rapae collected in Yakutsk and acclimated to laboratory conditions that closely 438 mimic environmental temperature and photoperiod of autumn in Yakutsk will be freeze tolerant.

4404.2 Yakutsk populations exhibit greater plasticity in cold tolerance physiology than London 441 populations

442 We observed little inter-population variation in whole organism cold tolerance metrics when $P$. 443 rapae pupae were acclimated to laboratory conditions $\left(4^{\circ} \mathrm{C}\right.$ for 12 weeks) in 2017 . Both 444 Yakutsk and London populations were freeze avoidant, froze at similar temperatures (mean 
445 SCPs of $-20.8{ }^{\circ} \mathrm{C}$ and $-24.4{ }^{\circ} \mathrm{C}$, respectively), and all pupae tested were able to survive at $-15^{\circ} \mathrm{C}$ 446 for two weeks. Unlike in P. apterus and C. costata (Rozsypal and Koštál, 2018; Shimada and

447 Riihimaa, 1988), external nucleation of ice formation at a high sub-zero temperature did not 448 induce freeze tolerance. However, when we supercooled ( 2 weeks at $\left.-15{ }^{\circ} \mathrm{C}\right)$ acclimated Yakutsk 449 and London pupae (2017), we detected inter-population differences at the suborganismal level.

450 We observed substantial plasticity in hemolymph composition (increased osmolality and 451 metabolite concentrations) of Yakutsk P. rapae in response to supercooling, unlike their London 452 counterparts. Although dehydration alone can increase hemolymph osmolality (e.g. Bennett et 453 al., 2005), our metabolomics results suggest that Yakutsk pupae altered hemolymph osmolality 454 through cryoprotectant synthesis. We did not see a uniform increase in metabolite concentrations 455 (which we would expect with dehydration) in supercooled Yakutsk pupae: glycerol and mannitol increased by more than 30-fold, while proline concentrations merely doubled (Fig. 5), and serine and succinic acid concentrations decreased (see supplementary data). Synthesis of cryoprotective metabolites can underlie substantial increases in cold tolerance, both over short (e.g. $<6 \mathrm{~h}$ in $B$. antarctica) and long (e.g. 6 weeks in G. veletis) time scales, even when metabolic rates are suppressed (Lee et al., 2006; Michaud et al., 2008; Toxopeus et al., 2019a). This plasticity may also be important for switches in cold tolerance strategy; for example, E. solidaginis from low 462 latitudes $\left(29^{\circ} \mathrm{N}\right)$ depress their SCP (avoid freezing) in late autumn, but accumulate additional cryoprotectants (glycerol) and become freeze-tolerant in mid-winter (once environmental 464 temperatures decrease below this SCP; Baust and Lee, 1981). Thus, although we were unable to 465 compare freeze tolerance and freeze avoidance in a common-garden approach, our results suggest a role for plasticity in cold tolerance of the more cold-adapted (Yakutsk) population of $P$. 467 rapae.

470 Similar to many insects, cold tolerance varied with development stage in $P$. rapae. Summer471 collected $P$. rapae larvae from Yakutsk (2016) were partially freeze-tolerant. Early autumn 472 temperatures in Yakutsk can drop below $0{ }^{\circ} \mathrm{C}$ (en.climate-data.org), and larval partial freeze 473 tolerance may facilitate survival of sub-zero temperatures prior to pupation. Larvae decreased 474 their SCP in response to starvation, similar to freeze-avoidant insects that clear their gut to 
475 remove exogenous ice nucleators (e.g. Olsen and Duman, 1997). Larval SCP also decreased 476 following multiple freezing events, similar to repeatedly-frozen larvae of Syrphus ribesii (Brown 477 et al., 2004). The mechanism underlying this response to repeated freezing is unknown, and we 478 speculate that dehydration (loss of freezable water) or rapid cryoprotectant synthesis between 479 freezing events could cause the SCP depression we observed over time. Cold tolerance increased 480 with pupation and entry into diapause, as pupae became freeze-tolerant (2002-2003) or freeze481 avoidant with low SCPs $(2014,2017)$. Diapause pupae had lower metabolic rates than non482 diapause pupae, consistent with many insects (Hahn and Denlinger, 2011), likely facilitating 483 overwintering survival by conserving energy reserves (Sinclair, 2015).

In addition to developmental and metabolic changes, we identified biochemical changes that could facilitate $P$. rapae cold tolerance. Most cold-hardy insects accumulate low molecular weight cryoprotectants (Lee, 2010; Toxopeus and Sinclair, 2018), and even moderate (e.g. c. 20 $\mathrm{mM}$ ) increases in concentrations of these low molecular weight metabolites can enhance cold tolerance, both in chill-susceptible (e.g. Koštál et al., 2012) and cold-tolerant species (e.g.

490 Toxopeus et al., 2019a). Supercooled Yakutsk $P$. rapae pupae accumulated potential 491 cryoprotectants similar to other freeze-tolerant insects, including c. $85 \mathrm{mM}$ proline (cf. Koštál et 492 al., 2011; Toxopeus et al., 2019a), c. $60 \mathrm{mM}$ alanine (cf. Michaud et al., 2008), and c. $30 \mathrm{mM}$ 493 sorbitol (cf. Baust and Lee, 1981). Proline has a demonstrated in vivo role in insect freeze 494 tolerance (Koštál et al., 2016; Toxopeus et al., 2019a), and its accumulation likely enhances cold 495 tolerance in P. rapae. We measured hemolymph [trehalose] > $50 \mathrm{mM}$ in both London and 496 Yakutsk $P$. rapae pupae, within the range of concentrations seen in freeze-avoidant and freeze497 tolerant species (Purać et al., 2016). This common cryoprotectant may facilitate cold tolerance in 498 both $P$. rapae populations.

500 In addition to low molecular weight cryoprotectants, we investigated inter-population differences 501 in hemolymph ice-binding agents. Freeze-tolerant insects often produce hemolymph ice502 nucleating agents (INAs) that initiate ice formation at high sub-zero temperatures (Toxopeus and 503 Sinclair, 2018), as previously detected in lepidopterans from Yakutsk (Li, 2012). We did not see 504 the elevated SCPs indicative of hemolymph INAs in pupae from either London or Yakutsk in 
5052014 or 2017, and speculate that our acclimation conditions were not appropriate to induce INA 506 accumulation (although we did not directly measure INA activity). However, we detected

507 spicular or hexagonal ice crystals in most Yakutsk (but few London) hemolymph samples

508 (2017), suggesting the presence of other ice-binding agents. All of the hemolymph samples we

509 tested had minimal thermal hysteresis $\left(<0.05{ }^{\circ} \mathrm{C}\right)$, suggesting that these ice-binding agents are

510 not antifreeze proteins that impart thermal hysteresis. For example, ice-binding proteins in the

511 Antarctic nematode Panagrolaimus davidi do not exhibit thermal hysteresis, but can still modify

512 ice growth by inhibited recrystallization (Wharton et al., 2005). Further studies may reveal a role

513 for these ice-binding agents in extremely cold-tolerant populations of $P$. rapae.

\section{5. Conclusions}

516 We demonstrated that $P$. rapae can be freeze-avoidant, freeze-tolerant, or partially freeze-

517 tolerant, and that cold tolerance strategy varies with developmental stage, population and

518 acclimation. Notably laboratory acclimations failed to induce freeze tolerance in diapause pupae

519 from Yakutsk (Russia), a population that is historically freeze-tolerant when overwintering in

520 natural conditions. Cold tolerance was surprisingly invariable among populations when we

521 acclimated pupae from Yakutsk (extreme winters) and London, Canada (mild winters) to

522 common-garden conditions. However, exposure to subzero temperatures induced plastic

523 responses (e.g. increased cryoprotectant concentrations) in Yakutsk, but not London, pupae. We

524 suggest that this plasticity is important for increasing cold tolerance in populations of $P$. rapae

525 that survive extreme winters (i.e. in Yakutsk).

\section{Abbreviations}

528 ANCOVA, analysis of covariance

529 ANOVA, analysis of variance

530 CTS, cold tolerance strategy

531 GC-FID, gas chromatography-flame ionization detection 
532 GC-MS, gas chromatography-mass spectrometry

533 INA, Ice-nucleating agent

534 LC-MS, liquid chromatography-mass spectrometry

535 PC, principal component

536 PCA, principal component analaysis

537 SCP, supercooling point

$538 \dot{V} \mathrm{CO}_{2}$, rate of carbon dioxide emission

539

540 Acknowledgements

541 The authors would like to thank Gregory Em and Osereiman Akioyamen for help with P. rapae

542 collection and rearing, Vladimír Koštál and the Laboratory of Analytical Biochemistry at the

543 Czech Academy of Sciences for assistance with processing and analyzing the metabolomics

544 samples.

546 Declaration of interest

547 None. The authors have no competing interests to declare.

\section{$549 \quad$ Funding}

550 This work was funded by an INTERACT Transnational Access grant to NGL, JGS and BJS, 551 Sakha Government Grant to promote innovations to NGL, a Natural Sciences and Engineering 552 Research Council of Canada (NSERC) Discovery Grant funding to BJS, and an NSERC Canada 553 Graduate Scholarship and a Company of Biologists Travelling Fellowship to JT. 
All data collected in this study are available in the supplementary data files.

\section{References}

Addo-Bediako, A., Chown, S.L., Gaston, K.J., 2000. Thermal tolerance, climatic variability and latitude. Proc. R. Soc. B. 267, 739-745.

Baust, J.G., Lee, R.E., 1981. Divergent mechanisms of frost-hardiness in two populations of the gall fly, Eurosta solidaginsis. J. Insect Physiol. 27, 485-490.

Brown, C.L., Bale, J.S., Walters, K.F.A., 2004. Freezing induces a loss of freeze tolerance in an overwintering insect. Proc. R. Soc. B 271, 1507-1511.

Clarke, A., 2017. Principles of Thermal Ecology: Temperature, Energy and Life. Oxford University Press, New York.

Crosthwaite, J.C., Sobek, S., Lyons, D.B., Bernards, M.A., Sinclair, B.J., 2011. The overwintering physiology of the emerald ash borer, Agrilus planipennis Fairmaire (Coleoptera: Buprestidae). J. Insect Physiol. 57, 166-173.

Bennett, V.A., Sformo, T., Walters, K., Toien, O., Jeannet, K., Hochstrasser, R., Pan, Q., Serianni, A.S., Barnes, B.M., Duman, J.G., 2005. Comparative overwintering physiology of Alaska and Indiana populations of the beetle Cucujus clavipes (Fabricus): roles of antifreeze proteins, polyols, dehydration and diapause. J. Exp. Biol. 208, 4467-4477.

Hahn, D.A., Denlinger, D.L., 2011. Energetics of insect diapause. Annu. Rev. Entomol. 56, 103-121.

Jensen, D., Overgaard, J., Sørensen, J.G., 2007. The influence of developmental stage on cold shock resistance and ability to cold-harden in Drosophila melanogaster. J. Insect Physiol. 53, 179-186.

Koštál, V., Korbelová, J., Poupardin, R., Moos, M., Šimek, P., 2016. Arginine and proline applied as food additives stimulate high freeze tolerance in larvae of Drosophila melanogaster. J. Exp. Biol. 219, 2358-2367.

Koštál, V., Šimek, P., Zahradníčková, H., Cimlová, J., Štětina, T., 2012. Conversion of the chill susceptible fruit fly larva (Drosophila melanogaster) to a freeze tolerant organism. Proc. Natl. Acad. Sci. U. S. A. 109, 3270-3274.

Koštál, V., Zahradníčková, H., Šimek, P., 2011. Hyperprolinemic larvae of the drosophilid fly, Chymomyza costata, survive cryopreservation in liquid nitrogen. Proc. Natl. Acad. Sci. U. S. A. $108,13041-13046$.

Kukal, O., Duman, J.G., 1989. Switch in the overwintering strategy of two insect species and latitudinal differences in cold hardiness. Can. J. Zool. 67, 825-827.

Lee, R.E., 2010. A primer on insect cold-tolerance. In: Denlinger, D.L., Lee, R.E. (Eds.), Low Temperature Biology of Insects. Cambridge University Press, New York, 3-34.

Lee, R.E., Elnitsky, M.A., Rinehart, J.P., Hayward, S.A.L., Sandro, L.H., Denlinger, D.L., 2006. Rapid cold-hardening increases the freezing tolerance of the Antarctic midge Belgica antarctica. J. Exp. Biol. 209, 399-406. 
Li, N.G. 2012. Relationships between cold hardiness, and ice nucleating activity, glycerol and protein contents in the hemolymph of caterpillars, Aporia crataegi L. Cryo-Lett. 33, 134142.

Li, N.G., 2016. Strong tolerance to freezing is a major survival strategy in insects inhabiting central Yakutia (Sakha Republic, Russia), the coldest region on earth. Cryobiology 73, 221-225.

Li, N.G., Averenskii, A.I., 2007. Cold adaptation in insects of Central Yakutia. Biophysics $52,436-439$.

Li, N.G., Osakovskii, V.L., 2008. On the flexibility of adaptation processes in cold-hardy insects. Biol. Bull. 35, 394-397.

Lighton, J.R.B., 2018. Measuring Metabolic Rates: A Manual for Scientists. Oxford University Press, New York.

Marshall, K.E., Sinclair, B.J., 2018. Repeated freezing induces a trade-off between cryoprotection and egg production in the goldenrod gall fly, Eurosta solidaginis. J. Exp. Biol. 221, jeb177956.

Marshall, K.E., Sinclair, B.J., 2012a.The impacts of repeated cold exposure on insects. J. Exp. Biol. 2015, 1607-1613.

Marshall, K.E., Sinclair, B.J., 2012b. Threshold temperatures mediate the impact of reduced snow cover on overwintering freeze-tolerant caterpillars. Naturwissenschaften 99, 3341.

Michaud, M.R., Benoit, J.B., Lopez-Martinez, G., Elnitsky, M.A., Lee, R.E., Denlinger, D.L., 2008. Metabolomics reveals unique and shared metabolic changes in response to heat shock, freezing and desiccation in the Antarctic midge, Belgica antarctica. J. Insect Physiol. 54, 645-655.

Mitchell, K.A., Sgrò, C.M., Hoffmann, A.A., 2011. Phenotypic plasticity in upper thermal limits is weakly related to Drosophila species distributions. Funct. Ecol. 25, 661-670.

Olsen, T.M., Duman, J.G., 1997. Maintenance of the supercooled state in the gut fluid of overwintering pyrochroid beetle larvae, Dendroides canadensis: role of ice nucleators and antifreeze proteins. J. Comp. Physiol. B. 167, 114-122.

Purać, J., Kojić, D., Petri, E., Popović, Ž.D., Grubor-Lajšić, G., Blagojević, D.P., 2016. Cold adaptation responses in insects and other arthropods: an "omics" approach. In: Raman, C., Goldsmith, M.R., Agunbiade, T.A. (Eds.), Short Views on Insect Genomics and Proteomics. Springer, New York, 89-112.

R Core Team, 2019. R: A Language and Environment for Statistical Computing. R Foundation for Statistical Computing, Vienna, Austria, http://www.R-project.org.

Richards, O.W., 1940. The biology of the small white butterfly (Pieris rapae), with special reference to the factors controlling its abundance. J. Anim. Ecol. 9, 243-288.

Ring, R.A., 1982. Freezing-tolerant insects with low supercooling points. Comp. Biochem. Physiol. A. 73, 605-612.

Rozsypal, J., Koštál, V., 2018. Supercooling and freezing as eco-physiological alternatives rather than mutually exclusive strategies: A case study in Pyrrhocoris apterus. J. Insect Physiol. $111,53-62$. 
Rozsypal, J., Moos, M., Šimek, P., Koštál, V., 2018. Thermal analysis of ice and glass transitions in insects that do and do not survive freezing. J. Exp. Biol. 221, jeb. 170464.

Ryan, S.F., Lombaert, E., Espeset, A., Vila, R., Talavera, G., Dincă, V., Doellman, M.M., Renshaw, M.A., Eng, M.W., Hornett, E.A., 2019. Global invasion history of the agricultural pest butterfly Pieris rapae revealed with genomics and citizen science. Proc. Natl. Acad. Sci. U. S. A. 116, 20015-20024.

Salt, R.W., 1961. Principles of insect cold hardiness. Ann. Rev. Entomol. 6, 55-74

Schou, M.F., Mouridsen, M.B., Sørensen, J.G., Loeschcke, V., 2017. Linear reaction norms of thermal limits in Drosophila: predictable plasticity in cold but not in heat tolerance. Funct. Ecol. 31, 934-945.

Shimada, K., Riihimaa, A., 1988. Cold acclimation, inoculative freezing and slow freezing: essential factors contributing to the freezing-tolerance in diapausing larvae of Chymomyza costata (Diptera, Drosophilidae). Cryo-Lett. 9, 5-10.

Sinclair, B.J., 1999. Insect cold tolerance: how many kinds of frozen? Eur. J. Entomol. 96, 157-164.

Sinclair, B.J., 2015. Linking energetics and overwintering in temperate insects. J. Therm. Biol. 54, 5-11.

Sinclair, B.J., Coello Alvarado, L.E., Ferguson, L.V., 2015. An invitation to measure insect cold tolerance: methods, approaches, and workflow. J. Therm. Biol. 53, 180-197.

Sinclair, B.J., Williams, C.M., Terblanche, J.S., 2012. Variation in thermal performance among insect populations. Physiol. Biochem. Zool. 85, 594-606.

Sømme, L., 1982. Supercooling and winter survival in terrestrial arthropods. Comp. Biochem. Physiol. A. 73, 519-543.

Toxopeus, J., Koštál, V., Sinclair, B.J., 2019a. Evidence for non-colligative function of small cryoprotectants in a freeze-tolerant insect. Proc. Royal Soc. B 286, 20190050.

Toxopeus, J., Lebenzon, J.E., McKinnon, A.H., Sinclair, B.J., 2016. Freeze tolerance of Cyphoderris monstrosa (Orthoptera: Prophalangopsidae). Can. Entomol. 148, 668-672.

Toxopeus, J., McKinnon, A.H., Štětina, T., Turnbull, K., Sinclair, B.J., 2019b. Laboratory acclimation to autumn-like conditions induces freeze tolerance in the spring field cricket Gryllus veletis (Orthoptera: Gryllidae). J. Insect Physiol. 113, 9-16.

Toxopeus, J., Sinclair, B.J., 2018. Mechanisms underlying insect freeze tolerance. Biol. Rev. 93, 1891-1914.

Wharton, D.A., Barrett, J., Goodall, G., Marshall, C.J., Ramløv, H., 2005. Ice-active proteins from the Antarctic nematode Panagrolaimus davidi. Cryobiology 51, 198-207.

Zachariassen, K.E., Andersen, J., Maloiy, G.M.O., Kamau, J.M.Z., 1987. Transpiratory water loss and metabolism of beetles from arid areas in East Africa. Comp. Biochem. Physiol. A. 86, 403-408. 